\title{
Eight Thousand Million People by the Year 2010?
}

One of the most frequently repeated imbecilities in the world today is that in $\mathbf{3 0}$ or so years' time there will be twice as many people living on the Earth. This statement is bandied about because if the population of the globe were to continue to multiply at approximately the same rate as it has been doing for the last few years, the population would indeed double in about 35 years. Unfortunately, however, a long history of exponential population growth in no way implies a long future. Although it may be theoretically possible at some time in the future to support 8 thousand million people temporarily, even the most casual examination of ecological constraints under which mankind must operate and of the lamentable failure of human political and social systems to produce an equitable and efficacious distribution of the world's limited resources, make it clear that the probability of supporting 8 thousand million people by 2010 is vanishingly small.

Consider briefly just the ecological constraints. Humanity is utterly dependent for its existence upon the functioning of immense and complex ecological systems. The conditions that make Earth hospitable to human life result from complex and perhaps fragile balances among the great chemical cycles-water, nitrogen, carbon, oxygen, phosphorus, sulphurall powered by the energy of the sun. Deadly ultraviolet rays are filtered out of the sun's radiation by a minute trace of ozone in the atmosphere, and traces of carbon dioxide and water vapour keep the surface temperature of the planet within limits tolerated by present-day organisms. Some of those organisms, in turn, regulate the environmental concentrations of nitrites, ammonia, and hydrogen sulphide - all poisonous to most forms of life. Over the long term, organisms also control the atmospheric concentrations of oxygen and nitrogen.

Today 4 thousand million people depend on such free 'service' functions of ecosystems for the preservation of the atmosphere, for the bulk of their waste disposal, for most of the nutrient cycling that is essential to the production of all their food, and for the maintenance of a great store of genetic information from which new crops, domestic animals, biological pest controls, and antibiotics, will come. Furthermore, almost all potential pests of our crops are controlled by Nature, not by Man, and almost all fish and shellfish - the source of perhaps 10 to 20 per cent of the animal protein consumed by mankind-are produced by natural ecosystems. Natural vegetation reduces floods, helps to prevent erosion, moderates local weather conditions, and affects the albedo (and thus the global weather-balance). Soils themselves are the product of the interaction of an enormous variety of living organisms with inorganic particles which the plants and animals help to fragment from rocks.

As incomplete as our knowledge may be concerning the vital operation of the natural systems that support human life, one cardinal principle seems clear: the ability of these systems to persist and perform their functions in the face of inevitable environmental change is related to the complexity of these systems. The more species of plants, animals, and microorganisms, that have coevolved to share the energy flowing through an ecosystem, the more stable the system is likely to be-in other words, the less likely it is that small changes in conditions will cause major disruptions.

Mankind has been a relentless enemy of coevolved complexity in ecological systems - and hence a destabilizing forceat least since the agricultural revolution (the hunting activities of human beings may have been a factor in the extinction of some large mammals even earlier). Agriculture itself is the practice of replacing coevolved natural ecosystems with simple artificial ones based on a few strains of highly productive crops. These croplands ordinarily require constant vigilance and inputs of energy (in the form of cultivation, fertilizers, pesticides, and so forth) to stave off the collapse to which their biological simplicity makes them prone. Even with prodigious effort, however, it is unlikely that mankind could maintain this perilous enterprise for long without support from natural systems.

Earth is now littered with the remains of other civilizations that failed to come to grips with the ecological constraints imposed upon society: the hydraulic civilization of the Tigris and Euphrates valleys, the classic Mayans, the ancient Khmers, and the Roman Empire, are only a few examples. While history books sometimes tend to credit these collapses to mysterious life-cycles within the civilizations themselves, the record of silted irrigation canals, salted and laterized soils, deforestation, erosion, and the like, is clear for those who know how to read it. Fortunately, the civilizations that fell victim to earlier ecocatastrophes were relatively localized. Today so-called 'western' civilization embraces the entire planet.

Many ecologists believe that an essential accompaniment to the intensively exploitive activities of mankind on land and increasingly in the oceans must be preservation of extensive, lightly exploited natural communities to serve as ecological buffers and reservoirs of diversity. Failure to establish such preserves and to protect our agricultural resources as carefully as possible could spell the end of our civilization as surely as a full-scale nuclear war, though perhaps less quickly.

Today one of the best measures of the assault humanity is mounting against the all-important natural systems that support it is the level of society's energy consumption. The simplifying processes of agriculture are increasingly powered by inanimate energy, and so is the destruction of farmlands through paving and 'development'. The processes that lead to the release of hundreds of thousands of new synthetic compounds into the environment are energy-intensive-and these compounds often have profound effects on the living organisms of Earth, which have no prior evolutionary experience with them. One can also regard per caput energy consumption as an index of the physical activity of a society-its moving of materials and people, its transforming of materials, its changing of temperatures, and so on. In virtually all circumstances, these activities exact a cost from natural environmental systems.

In MIT's prestigious Study of Critical Environmental Problems (SCEP), a majority of the global problems considered were directly involved with energy use. The fundamentally intractable problem of thermal pollution is shared by both

Environmental Conservation, Vol. 2, No. 4, Winter 1975-(C) 1975 The Foundation for Environmental Conservation-Printed in Switzerland. 
nuclear and fossil-fuelled power technologies (at present nuclear is somewhat worse in this regard). If the 'historic growth' scenario of the Ford Foundation's Energy Report (3.4\% energy growth per annum, the 1950-70 U.S. average) is applied to the world, the associated heat-release alone would almost certainly disrupt global climate significantly within about a century, with serious ecosystemic consequences, while climatic disruption by the $\mathrm{CO}_{2}$ and particles from fossil-fuel combustion could occur much sooner.

What if we could miraculously develop a source of cheap, abundant power that was nearly 'pollution-free' (e.g., solar or a much-improved nuclear technology)? Some of the environmental problems considered in SCEP would be abated. Carbon dioxide concentrations in the atmosphere would drop, as would particulates from direct energy use, and the problems of oil pollution and containment of radioactive wastes would be reduced or eliminated. Under any reasonable scenario about the uses to which superabundant energy would be put, however, one would expect other problems (most of which are considered in $S C E P$ ) to be exacerbated: atmospheric particulates from farming marginal land, particulates from mining lower-grade ores (including perhaps common rock), particulates from off-road vehicles, formation of contrails, injection of synthetic organic poisons into the biosphere, destruction of estuaries, and so on. As the population grew from 4 thousand millions towards 8 , the attempt clearly would be made to pave, develop, industrialize, and exploit, every last bit of the planet-a trend that would inevitably lead to a collapse of the life-support systems upon which that growing population would depend.

Such a collapse could take many forms. One might be the complete loss of oceanic fisheries through a combination of overfishing, marine pollution, and the destruction of estuaries. This in turn could lead to global famine developing as a key source of protein was removed from a world already on a nutritional knife-edge. On the other hand, the end of civilization might be triggered by weather changes induced by world-wide attempts at 'development' - weather changes to which agricultural systems could no longer respond because the decay of genetic variability of crops (one of today's most serious environmental problems) had proceeded too far. Or the end might be heralded by the rapid destruction of the ozone shield, posing a direct threat to Homo sapiens as well as to all the ecosystems of the planet. Or, as has often been predicted, the accumulation of poisonous wastes might simply swamp the natural disposal systems, making air unbreathable and water unpotable.

Most likely, of course, is a combination of such events, as mankind, largely ignorant of both the functioning of ecological systems and the nature of human attacks upon them, follows the growth-maniacs and the pied pipers of technology all the way to destruction. Those who believe that science will pull a technological rabbit out of the hat to save us at the last minute simply suffer from an inability to learn. Technological rabbits tend to create more problems than they solve -they usually have large appetites and abundant noxious droppings. The 'green revolution', broadcast use of antibiotics and chlorinated hydrocarbon pesticides, dependence on the automobile for personal transportation, and today's primitive nuclear power systems, are prime examples.

Therefore when one talks about having 8 thousand million people in the year 2010 one must ask what are the possibilities that a sequence of events leading to ecosystem collapse can be avoided. We think that such a world can be designed in theory, but the theory would have to neglect all the realities of human behaviour. One hardly needs special expertise to evaluate the likelihood that human society will reform to the point where the kind of 'Faustian bargain' that was envisioned by Alvin Weinberg can be made-not just relative to those technological rabbits, but with Mother Nature herself.

In short, believing that there will be 8 thousand million people in the year 2010 is somewhat akin to believing in Santa Claus. We will indeed be fortunate if the world can support 4 thousand millions in the year 2010, and the population size may well be much less than that - as a result of a continuing sequence of disasters and a general deterioration of the carrying capacity of the planet. If by some combination of unlikely events there are 8 thousand million people alive in A.D. 2010, it will be a fairly sure bet that their very presence and the techniques used to support them will be mortgaging the future of all humanity - dramatically degrading the environment and reducing future carrying capacities. It is always important to remember that the question is not just 'How many people can we support' but 'How many people can we support, with what standard of living, and for how long.' And of course there is always that ultimate question: 'Why have more people?'

\author{
Paul R. EhrLich \\ Professor of Biology and Director of Graduate Studies \\ Stanford University
}

$\&$ 